\title{
Impact of Ocean Mean Dynamic Topography on Satellite Data Assimilation
}

\author{
F. BIROL \\ J. M. BRANKART \\ F. CASTRUCCIO \\ P. BRASSEUR \\ J. VERRON
}

\section{QUERY SHEET}

Q1: Au: Pls. spell out "LEGI."

Q2: Au: Provide keywords.

Q3: Au: Provide received and accepted dates.

Q4: Au: Provide E-mail.

Q5: Au: No Bleck 2002 in Refs. Do you mean Bleck and Boudra 1981?

Q6: Au: Spellout RSMAS?

Q7: Au: No Large in refs. Pls. add.

Q8: Au: Spellout in first use "EOFs."

Q9: Au: Not in refs. Pls. add.

Q10: Au: Not in refs. Pls. add.

Q11: Au: Not in refs. Pls. add.

Q12: Au: Refs. have Frantatoni which?

Q13: Au: See Q12.

Q14: Au: Not in refs. Pls. add.

Q15: Au: Text, p. 10, has "frantatoni" which?

Q16: Au: Pls. provide page range? 


\section{Impact of Ocean Mean Dynamic Topography on Satellite Data Assimilation}

F. BIROL

J. M. BRANKART

F. CASTRUCCIO

P. BRASSEUR

J. VERRON

LEGI, Grenoble, France

The response of an eddy-permitting ocean model to changes imposed by the use of different mean dynamic topographies (MDT) is analyzed in a multivariate assimilation context, allowing the evaluation of this impact, not only on the surface circulation, but also on the interior ocean representation. The assimilation scheme is a reduced-order sequential Kalman filter (SEEK). In a first set of experiments, high resolution sea surface temperature, along-track sea surface height and sea surface salinity from climatology are assimilated into a $1 / 3^{\circ}$ resolution North and Tropical Atlantic version of the HYCOM model. In a second experiment, in situ profile data are assimilated in addition to the surface measurements.

The first set of experiments illustrates that important differences in the representation of the horizontal model circulation pattern are related to differences in the MDT used. The objective of assimilation is to improve the representation of the $3 D$ ocean state. However, the imperfect representation of the mean dynamic topography appears to be an important limiting factor with regard to the degree of realism obtained in the simulated flow.

Vertical temperature and salinity profiles are key observations to drive a general circulation ocean model toward a more realistic state. The second set of experiments shows that assimilating them in addition to sea surface measurements is a far from trivial exercise. A specific difficulty is due to inconsistencies between the dynamic topography diagnosed from in situ observations and that diagnosed from sea surface height. These two fields obtained from different data sources do not contain exactly the same information. In order to overcome this difficulty, a strategy is proposed and validated.

Keywords

Data assimilation for oceanographic applications has entered a new era since the advent of satellite missions that allow accurate measurements with high resolution and global coverage. In particular, radar altimetry provides quasi-global observations of the sea surface height (SSH) measured with respect to the reference ellipsoid. For this reason, $\mathrm{SSH}$ measurements have become one of the most important contributions to ocean prediction systems. However, the physical quantity that reflects the dynamic state of the ocean is the absolute

Received ; accepted .

This work was conducted within the framework of the TOPAZ project (Grant EVK3-2000-00601). We would like to thank Eric Chassignet (RSMAS) for providing the model configuration and the MICOM mean sea surface, Fabrice Hernandez and Eric Greiner (CLS) for MDT1 data, Pascal Legrand (LPO/IFREMER) for MDT2 data, and Catherine Maillard (SYSMER/IFREMER) for the XBT database.

Address correspondence to F. Birol, LEGI, BP53, 38041 Grenoble Cedex 9, France. E-mail: 
ocean dynamic topography, corresponding to altimetric SSH minus the geoid. The geoid is an equipotential gravity surface that is different from the reference ellipsoid. Unfortunately, until now geoid uncertainties have been too large, at the scale of major ocean circulation features, to allow using them for oceanographic purposes, and in particular for the derivation of the absolute dynamic topography. As a result, for most oceanographic applications in general and for data assimilation in particular, the use of altimetric signals has been limited to sea level anomalies (SLA), variations of the sea level about the mean sea level (computed over a certain time span). The CHAllenging Minisatellite Payload (CHAMP) mission (http://op.gfz-potsdam.de/champ/), launched in July 2000, was the first of a series of Geodetic missions that should lead to a precise estimate of the ocean geoid height and, consequently, to improved knowledge of absolute dynamic topography. In particular, the European Space Agency Gravity field and steady-state Ocean Circulation Explorer program (www.esa.int/esaLP/goce.html), scheduled for 2006, and the Gravity Recovery and Climate Experiment (GRACE) (http://op.gfz-potsdam.de/grace/index_GRACE.html), launched in 2002, are designed to provide the data set required to obtain an accurate geoid (around $10 \mathrm{~cm}$ error) at a high spatial resolution (around $80 \mathrm{~km}$ ). However, while substantial progress should be made in this field following these missions, the delivery of a product with sufficient precision will still take several years.

Since the quantity that can be assimilated in ocean circulation models is the absolute dynamic topography, we need to add information about the mean ocean state to the altimetric SLA. This distance between the geoid and the mean level of the ocean is called the Mean Dynamic Topography (MDT). (Note that the MDT is usually called mean sea surface height by ocean modelers, since most ocean models use a spherical geoid so that both quantities are identical). Different studies have provided different MDT products, with different characteristics and accuracy. A number of approaches exist. An inverse model of the ocean circulation constrained by observations can provide an estimate of the MDT (Mercier 1986). A synthetic geoid approach consisting of combining satellite altimetry and in situ data can also be considered (Mitchell et al. 1990). Another approach is based on ocean model sea surface representation, with or without assimilation (Killworth et al. 2001). These different methods provide descriptions of the mean ocean circulation that are not necessarily the same.

Because of geostrophic balance, ocean surface currents are proportional to the gradient of sea surface height. The change in the slope of the sea level elevation imposed by the assimilation is expected to modify the simulated surface circulation. Surface currents as well as absolute dynamic topography contain the integrated signature of ocean processes within the whole water column. Therefore assimilating this quantity also implies making a correction to the ocean thermohaline structure. The use of imprecise MDT products to compute the absolute value of the ocean dynamic topography will impact the simulated oceanic features. In addition to the sensivity of surface currents, it is important to determine to which extent the choice of a particular MDT has an impact on the interior ocean properties estimated by the assimilation system. Both ocean model and data assimilation schemes have now reached a degree of accuracy where the realism of the imposed MDT can constitute a major limitation in forcing ocean models towards reality on regional scales. This is why it appears important to study the impact of state-of-the-art MDT products on assimilation hindcasts. A better knowledge of the sensitivity of ocean simulations to MDT uncertainties can also lead to significantly improved estimates of MDT.

With extensive hydrographic programs like ARGO, we have now entered a phase where the challenge is to combine optimally surface and subsurface information into a single estimation process. Through these observations, it is expected to better control the representation of subsurface fields/water masses. This also leads to a number of relevant 
and challenging questions. Some recent studies have been conducted to explore the impact of the assimilation of sparse in situ data compared to satellite data, in terms of spatial and temporal resolution ( $\mathrm{Li}$ et al. 2003). A specific question that needs to be addressed here relates to whether the dynamic topography from in situ observations is consistent with that obtained by the addition of SLA and the imposed MDT in a multivariate assimilation system. Indeed, there is no reason why these two fields, which are different in nature, obtained from different data sources and associated with different kind of errors, should contain completely compatible information.

The present study aims to demonstrate the sensitivity of a system assimilating altimetric data to different available MDT products. The detailed validation of the MDTs, which can be addressed independently of any assimilative system, is not the objective here. Such a validation or quantitative comparison would be dependent on the model and assimilation

100 system used. Both the case where only sea surface data are assimilated and that where vertical temperature and salinity profiles are added are adressed. The next section describes the numerical model, assimilation method, and data sets. Following this, a section concentrates on problem definition and the experimental framework and another contains the results of the sensitivity study. Then a section deals with the specific question of the assim-

105 ilation of temperature and salinity (TS) profiles. Finally, a summary and conclusions are presented.

\section{Numerical Model, Assimilation Method and Data Sets}

\section{Numerical Model}

The circulation model used is HYCOM, the HYbrid Coordinate Ocean Model (Bleck 2002;

110 Chassignet et al. 2003; Halliwell 2004) developed at RSMAS. The computational domain is the North and Tropical Atlantic Ocean basin from $28^{\circ} \mathrm{S}$ to $70^{\circ} \mathrm{N}$, including all the Mediterranean Sea. The horizontal grid resolution is given by $1 / 3^{\circ} \times 1 / 3^{\circ} \cos (\phi)$, where $\phi$ is the latitude. The Northern and Southern boundaries are closed and relaxation to climatology is applied within a 30 grid-point zone adjacent to the wall. The bathymetry is interpolated

115 from the ETOPO5 database onto the model grid. Subgrid-scale mixing is parameterized using a biharmonic dissipation operator. Vertical mixing is governed by the K-Profile Parameterization (KPP) mixing scheme (Large et al. 1994).

The hybrid vertical coordinate is isopycnal in the open stratified ocean, z-level in the mixed layer and unstratified areas, and smoothly reverts to a terrain-following coordinate

120 in shallow coastal regions (Figure 1). In this version, the vertical density structure is represented by 26 hybrid layers. ${ }^{1}$ If the density of a given layer deviates from its isopycnic reference, the interfaces bounding this layer are adjusted, so that density is restored to its target value (adding denser or lighter water if the water is too light or too dense). If the layer interface approaches a prescribed minimum thickness, isopycnic conditions are not

125 entirely restored, and a cushion function is used to recalculate a vertical or sigma coordinate location (depending on bottom depth). The lower layers are isopycnic and exist only if the corresponding model target density of each layer exists; otherwise they collapse to zero thickness. Hydrographic and momentum equations have been modified to handle a generalized vertical coordinate. In each layer, both density and salinity are advected. The

130 theoretical basis for implementing the hybrid coordinate can be found in Bleck and Boudra (1981).

${ }^{1}$ The prescribed reference $\sigma_{\beta}$ values are: $19.5,20.25,21.0,21.75,22.5,{ }^{1} 23.25,24.0,24.77$, $25.28,25.77,26.18,26.57,26.8,27.03,27.22,27.38,27.52$, 27.64, 27.74, 27.82, 27.88, 27.94, 28.0, 28.06, 28.09 and 28.12 . 


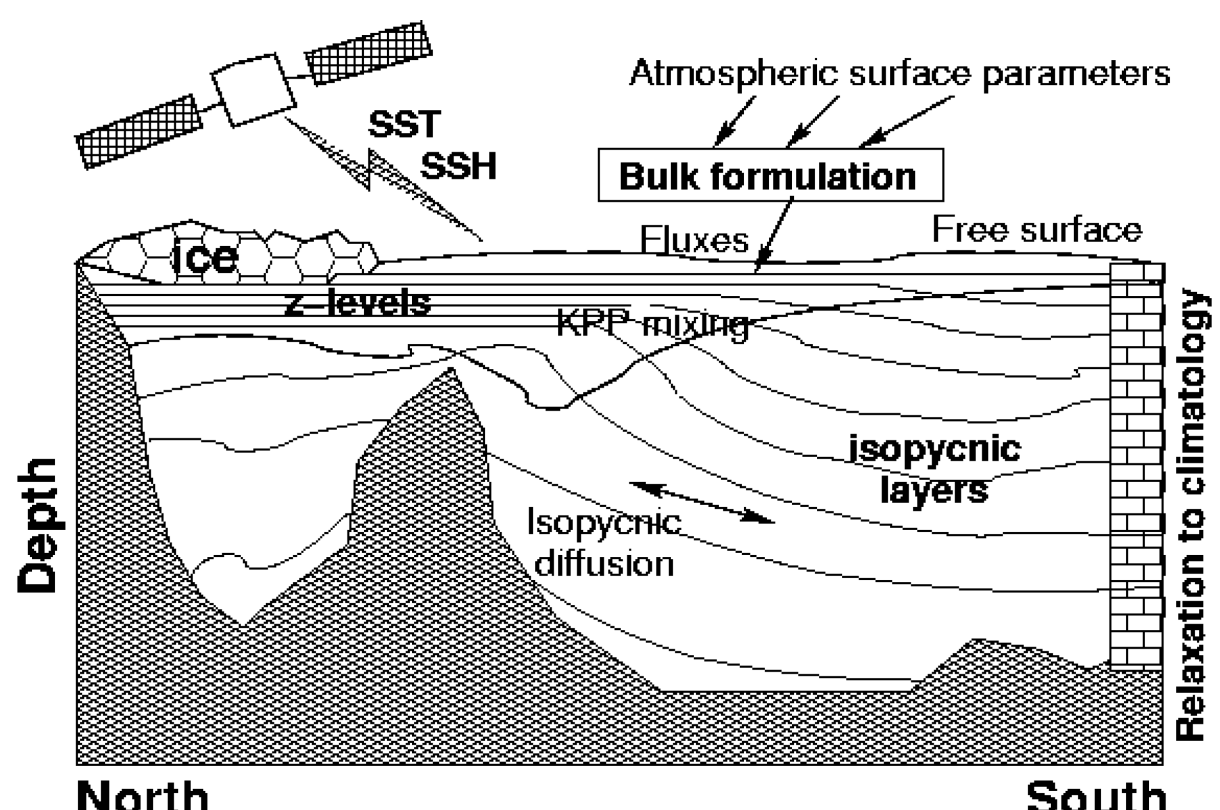

FIGURE 1 Sketch of the HYCOM model configuration.

The model is initialized using the Levitus climatology and is then spun up from rest during a 9-year time period, before running a 1985-1996 interannual experiment (without assimilation). Bulk formulation is used and the model is driven by wind stress, wind speed, air temperature and humidity, precipitation, and longwave and shortwave surface radiation. 135 During the spinup of the model, the forcing fields are derived from the Comprehensive Ocean-Atmosphere Data Set (COADS) monthly climatology. The sea surface salinity and sea surface temperature are relaxed towards the Levitus climatological fields with a 30-day timescale. During the 1985-1996 free model simulation and during the assimilation experiments, high frequency (every six hours) European Center for Medium-Range Weather $\mathbf{1 4 0}$ Forecasts (ECMWF) atmospheric data sets are used.

\section{Assimilation Method}

The assimilation method is derived from the SEEK filter, a reduced-order Kalman filter introduced by Pham et al. (1998). This sequential method has already been described and used in a number of studies (Brasseur et al. 1999; Penduff et al. 2002; Durand et al. 2003). In 145 the present implementation, we use the procedure described in detail by Brankart et al. (2003) and updated to take into account the hybrid nature of the vertical coordinate of HYCOM. The estimation vector is composed of the interface pressure, temperature and salinity for each of the 26 layers, in addition to the sea surface elevation. At every assimilation step, the misfit between observations and their model counterparts is evaluated and projected onto the dominant error modes. The background error is initialized using the system variability diagnosed from a free model run. In practice, we use the 10 dominant (EOFs) of a 3-year sample of model snapshots. A suboptimality is introduced in the scheme by keeping the background error covariance matrix unchanged from one assimilation cycle to the next. However, the use of spatially-dependant, three-dimensional, multivariate statistics derived from a free model integration relates the present method to a simplified, reduced-order Kalman filter. The gain is local, meaning that the control of a specified water column will depend only on the observations within a specified influence bubble. In practice, the size 
of each influence bubble is parameterized inside a box of $14 \times 14$ grid points. Observation errors are assumed to be independent; the corresponding prescribed values are given in section on data set which follows.

In order to reconcile statistical optimality with the physical constraints on the model state vector, an adjustment operator is introduced before model restart to restore the model constraints. A detailed justification of this operation can be found in Brankart et al. (2003), imilar approach was successfully applied to the MICOM model. The adjustment step consists of three main operations. First, we consider that the correlation between surface observations and the state variables at depth is not sufficiently reliable. In practice, only the state variables located inside the mixed layer are updated if TS profiles are not assimilated. Second, we restore the hydrostatic stability of the water column. The objective is to generate

170 a corrected analyzed state where layer density increases with depth and layer thicknesses are greater than their minimum value (HYCOM imposes a minimum thickness on each layer). In particular, if a layer has been reduced by too much during the statistical analysis, the excess reduction is transferred to the closest layer. Third, we apply a change along the Cooper and Haines mode (i.e., a vertical shift of the water column) to adjust the vertical structure of the water column to the analyzed dynamic topography (Cooper and Haines 1996).

\section{Data Sets}

\section{Sea Surface Topography}

The altimetric observations consist of along-track sea surface topography, obtained as the sum of TOPEX/Poseidon or ERS altimeter SLA, and the mean dynamic topography (see next section). The assimilation window is three days. Each analysis is computed using all the available data gathered within a 3-day interval (1.5 days before and after the analysis time). The accuracy of the SLA can be estimated at around $3 \mathrm{~cm}$, except in the coastal zones, where tidal corrections are less accurate. We therefore decided to mask SLA data where the bottom depth is less than $150 \mathrm{~m}$. In order to eliminate spurious effects due to the transition between zones where the model state is corrected by the assimilation of SLA and zones where it is not (corresponding to significant portions of the American and European continental shelves), we replace the sea surface topography by the mean dynamic topography part in such coastal areas. A bulk error of $3 \mathrm{~cm}$ RMS was prescribed on the total sea surface topography data in the assimilation system.

190 For the present study, three different MDTs for the North and Tropical Ocean, computed with three different methods, were collected and used to perform three different assimilation experiments. The first, referred to as MDT1, is the MDT from Rio and Hernandez (2002), the second, referred to as MDT2, is from Le Grand et al. (1998), and the third, referred to as MDT3, is derived from a $1 / 12^{\circ}$ Atlantic MICOM experiment (Chassignet and Garraffo 195 2001).

MDT1 is a $1^{\circ} \times 1^{\circ}$ product, estimated from a multivariate statistical analysis using hydrographic data, surface drifter velocities and altimetry over the 1993-1999 period. It is based on the SMO CLS01 mean sea surface (Hernandez et al. 2001) and the EIGEN2 geoid computed from CHAMP data. This MDT is produced to match the altimetric average re-

200 moval period (1993-1999); the associated drawback is that in situ and drifter measurements available during this period provide insufficient sampling in some areas.

MDT2 is a $1^{\circ} \times 1^{\circ}$ product obtained by merging in situ measurements and altimetric observations using a nonlinear inverse model (Mercier 1986). Hydrographic data come from a compilation of 70 years and altimetric observations cover the 1993-1996 period.

205 This approach is based on dynamical considerations but still strongly limited by resolution and accuracy of available data. 
a)

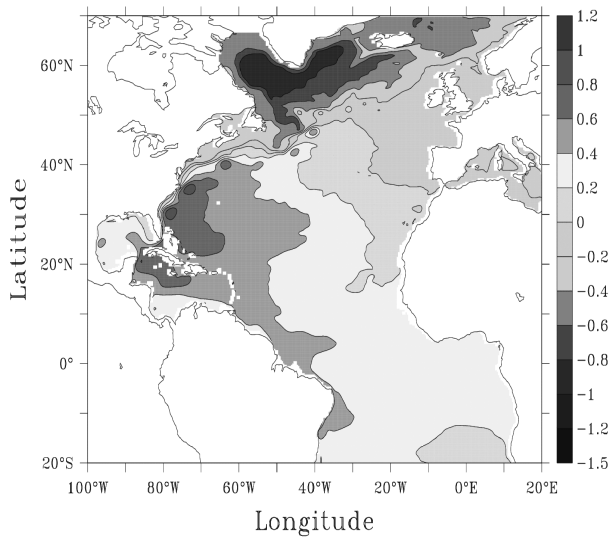

c)

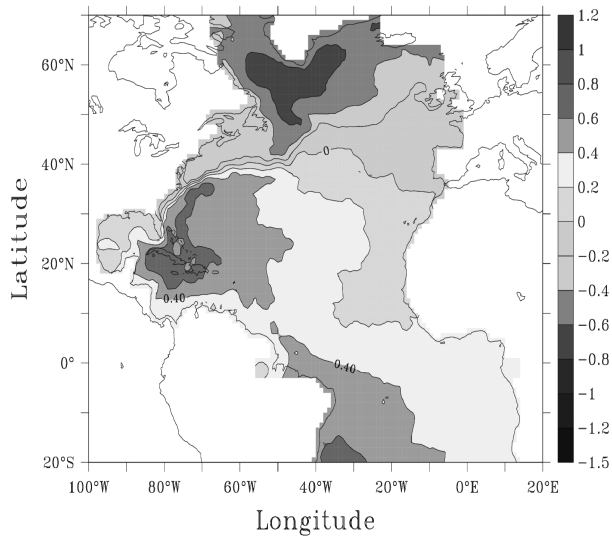

b)

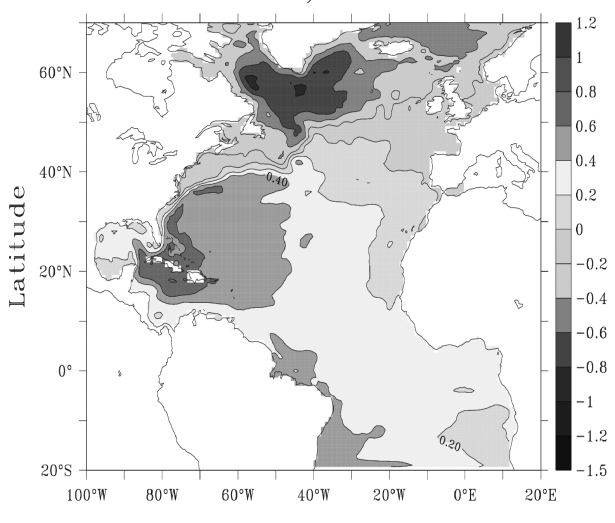

d)

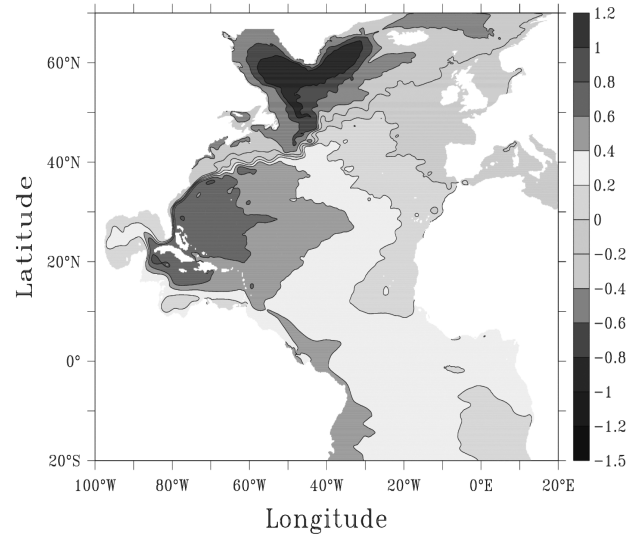

FIGURE 2 Mean Dynamic Topography (in meters): (a) MDT0, (b) MDT1, (c) MDT2, and (d) MDT3.

MDT3 is a 2-year average of a sea surface elevation time series from a $1 / 12^{\circ}$ Atlantic MICOM free run experiment performed with ECMWF forcing. This product has a high spatial resolution, but the associated mean field includes systematic model errors (mainly due to unresolved physics, numerical errors, errors in boundary conditions, or forcings).

Figure 2 shows these three different MDT fields, which roughly correspond to three available types of MDT estimates. The 4 -year average MDT computed from a $1 / 3^{\circ}$ Atlantic HYCOM free run experiment over the period 1993-1996 (named MDT0) is also shown for comparison. With regard to large-scale features, the four MDTs are fairly similar in terms of structure and amplitude, showing the classical picture of the mean ocean circulation in the $\mathbf{2 1 5}$ North and Tropical Atlantic Oceans. The signature of the main currents is present. All MDTs represent a realistic Gulf Stream separation at Cape Hatteras, except MDT0 that is affected by a significant model bias in the Gulf Stream region. The Gulf Stream (GS) overshoots in HYCOM $1 / 3^{\circ}$; this is a classical problem of ocean numerical models at eddy-permitting resolutions. The three MSSH fields differ mainly at the smaller scales, and also in their $\mathbf{2 2 0}$ representation of several regional circulation features. In broad terms, MDT2 is smoother than the other two. This is due to the longer period of observations used to compute this field. In MDT3, the Florida Current, the Gulf Stream and North Atlantic Current (NAC) front are sharper than in the other MDTs. This is due to a better representation of the 
225 strength of ocean currents in a $1 / 12$ degree grid mean than in a lower resolution mean. In MDT1, MDT2, and MDT3, the NAC front turns north around $45^{\circ} \mathrm{W}$, and then toward the northeast around $40^{\circ} \mathrm{W}$, forming the North Atlantic Drift Current along the eastern flank of the Reykjanes Ridge. Many small-scale discrepancies between the different MDTs can be observed all along the resulting fronts. Another quantitative difference can be found

230 in the subpolar gyre, with fronts associated with the Labrador Current and the East/West Greenland Current system that are significantly weaker in MDT2, illustrating a poorly defined subpolar gyre circulation.

An illustration of the differences of the Gulf Stream front representation by the different MDTs is given by Figure 3, which represents cross-sections of the three MDT products along

a)

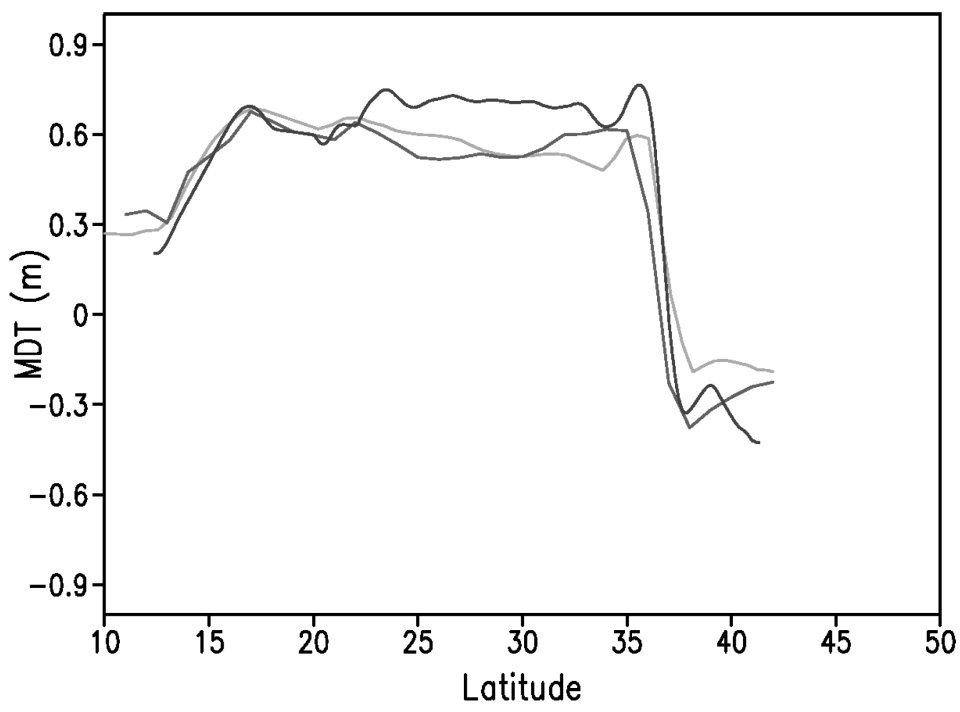

b)

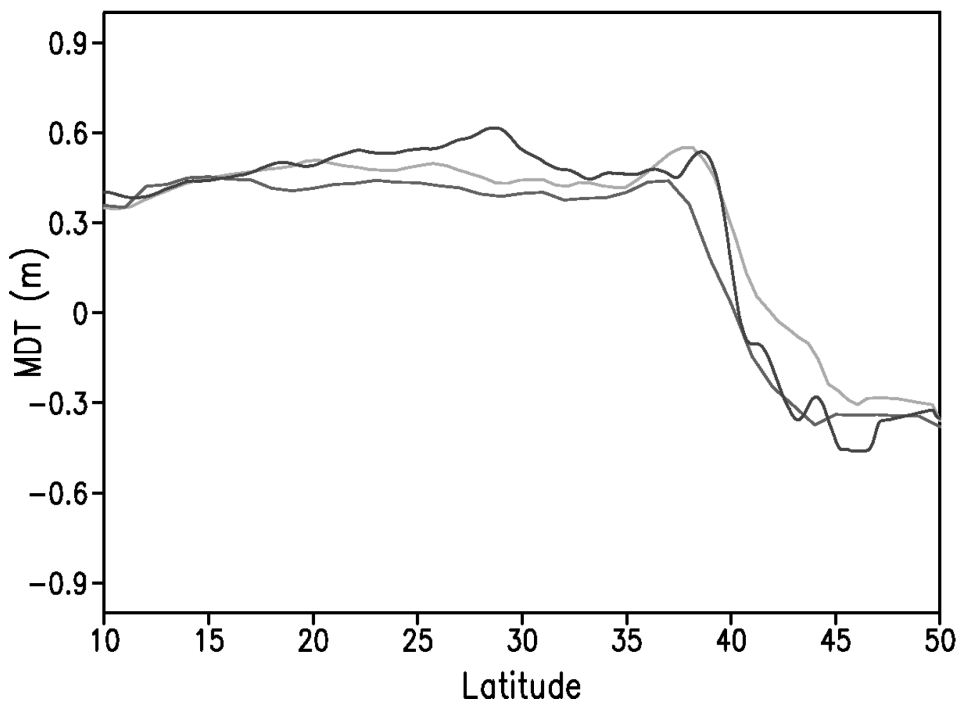

FIGURE 3 Section of the different mean dynamic topographies (in meters) (a) along $72^{\circ} \mathrm{W}$ and (b) along $55^{\circ} \mathrm{W}$. MDT1 is in green, MDT2 is in red, and MDT3 is in blue. 
$72^{\circ} \mathrm{W}$ (Figure 3a) and along $55^{\circ} \mathrm{W}$ (Figure 3b). Both sections cross the Gulf Stream front, 235 represented by a sharp MDT gradient. The difference across the Gulf Stream front is $10 \mathrm{~cm}$ larger in MDT3 than in MDT1 and MDT2. MDT1 has a weak front amplitude just off Cape Hatteras (20 cm lower than MDT2). MDT3 and, to a lesser extent MDT1, have secondary fronts south and north, associated to the inertial Gulf Stream recirculation, which are not present in MDT2. The Gulf Stream mean path is the same in MDT2 and MDT3, but is 240 different in MDT1, with a too Northern position (Figure 3b).

\section{Sea Surface Temperature and Salinity}

The Sea Surface Temperature (SST) observations assimilated in HYCOM consist of high-resolution composite AVHRR data (10 km resolution at the equator). The available SST data are gathered within the 3-day assimilation time window. An observation error $\mathbf{2 4 5}$ of $0.4^{\circ} \mathrm{C}$ is prescribed. The SST data coverage can be strongly limited by the presence of clouds, particularly at high latitudes and during the winter season.

For multivariate data assimilation, inaccuracies in the specification of forecast error covariances can lead to inappropriate corrections of unobserved fields like SSS. In order to avoid such problems, we assimilated Levitus 98 monthly climatological Sea Surface Salinity (SSS) in addition to SST and SSH. Unlike SST or SLA, SSS measurements are sparse both in time and space. The European Space Agency SMOS mission that will be launched in the near future will provide SSS data every 10 days at $200 \mathrm{~km}$ resolution, but at the present time there is no high resolution SSS data set available. Because climatological fields are very smooth, we introduce a smoothing operator into the observation operator $\mathbf{2 5 5}$ to compute the model equivalent to the data. In this way, only large-scale features in the model can be influenced by SSS data assimilation. For this reason, the error associated to the large-scale averaged SSS is set to 0.05 psu.

\section{In Situ Profiles}

We could have chosen WOCE temperature and salinity profiles as data sources for $\mathbf{2 6 0}$ our in situ data assimilation experiment. However, their spatial and temporal distribution remains sparse, with many sites having only temperature profiles and most of them having a poor vertical extension compared to local ocean depth. These features would have induced specific problems.

In the multivariate data assimilation experiment, we first want to illustrate important $\mathbf{2 6 5}$ aspects of the complementarity between surface and subsurface data. Thus, we have chosen to extract the assimilated profiles from the Levitus 98 monthly climatology. In order to enable assimilation into HYCOM, they are transformed into hybrid coordinates, so that observations of temperature, salinity, and interface pressure are available for each layer and are effectively assimilated. Note that correlations between interface pressure errors and layer TS errors have been dropped in the background error covariance. Observation errors have been set at $0.2^{\circ}, 0.1 \mathrm{psu}$, and $20 \mathrm{~m}$, respectively, for temperature, salinity, and pressure measurements. This information is used with an adequate observation operator (same treatment as for climatological SSS), so that it only influences the large-scale features of the 3-D TS structure.

\section{Problem Definition and Experimental Framework \\ Problem Definition}

Since information about the geoid is not sufficiently precise, the mean (MSSH) of the altimetric signal SSH has to be removed, so that only the altimetric residuals can be accessed. 
280 To obtain the quantity assimilated into the model, that is, the absolute ocean dynamic topography (ADT), a mean dynamic topography (MDT) must be added to the SLA. Ideally, this MDT should correspond exactly to the average state of the ocean over the time period corresponding to the altimeter measurements. One simple solution would be to use the model mean ocean state over this time period. Unfortunately, this variable is affected by significant ystematic errors, due to various model deficiencies. For this reason, it is necessary to use a more realistic mean ocean state. Our assimilation experiments will be performed by adding one of the MDT described in the section on data sets to the SLA.

Figure 4 illustrates the definition of the height measurements used. In summary:

$$
\mathrm{ADT}=\mathrm{SSH}-\mathrm{MSSH}+\mathrm{MDT} .
$$

MDT is a synthetic product and can then be altered by (1) errors associated with the data and the method used to compute this field, (2) bias related to nonuniform time and space coverage of the observation data sets used, and (3) bias introduced by the fact that the average state of the ocean is calculated over a time period which does not correspond to the altimeter measurements. These differences can lead to spurious effects in the assimilation experiments. Thus, let us define:

$$
\operatorname{MDT}(x, y)=S 0+S 1(x, y),
$$

where $\iint_{D} S 1(x, y) d x d y=0, D$ being the model ocean domain.

$S 1$ is due to permanent ocean circulation patterns that vary geographically and determines a specific shape of the MDT. $S 0$ is the horizontal mean difference between the geoid and the MDT. SO is then purely conventional and defines a reference surface parallel to the geoid. In a system covering the global ocean domain, $S 0$ is conventionally equal to 0 .

Problems arise because (1) the conventional reference may not be the same for the model and the data (for instance, our model is regional and was initialized with $S 0$ equal to 0 over the North and tropical Atlantic), and because (2) during the spinup, the model may have drifted from the initial climatological state. For these reasons, a significant horizontal mean difference exists between the MDT and the corresponding current model state. In the absence of vertical information (i.e., vertical profiles acting as an additional constraint in the assimilation system) that could track these misfits back to identifiable causes, no doubt we will face difficulties in interpreting this important part of the dynamic topography. This misfit can be of the same order of magnitude as the part due to sea-level variations. To account

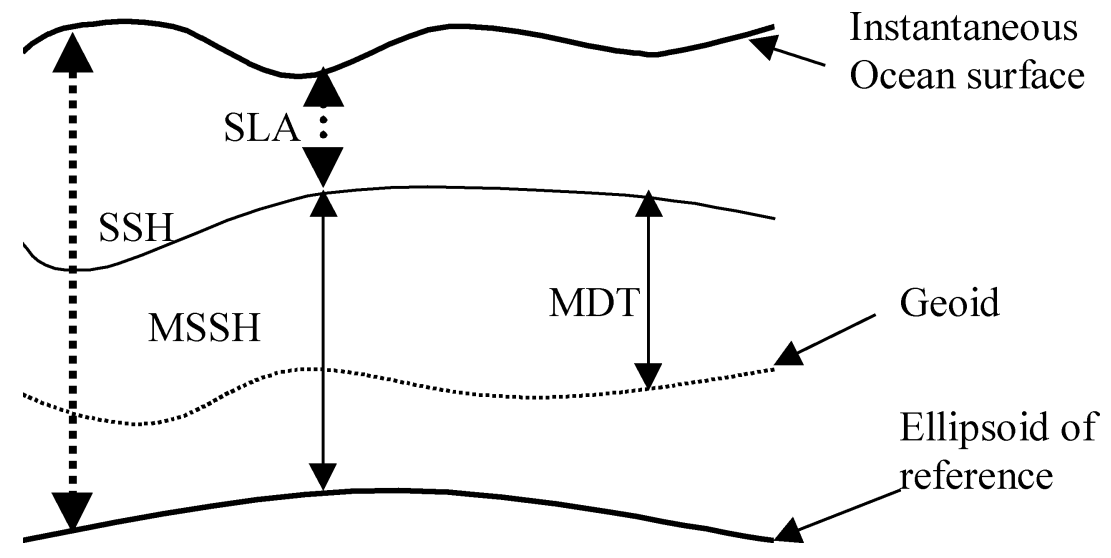

FIGURE 4 Definition of height measurements. 
for this problem, an averaged misfit value $S 0$ is introduced, characteristic of the current model state. The $S 0$ component is removed from the corresponding MDT field, meaning $\mathbf{3 1 0}$ that we do notcorrect the error corresponding to the model drift in the initial model state. Otherwise, layer interfaces could be shifted along the Cooper and Haines mode, resulting in unrealistic vertical displacement.

\section{Description of the Experiments}

In a first set of experiments, four simulations are performed between October 1992 and $\mathbf{3 1 5}$ December 1993. The first (called EXPT0) is a free-run simulation, without assimilation. It is defined as the control run. The other three differ from the first in terms of the assimilation of sea surface temperature, sea surface salinity, and sea surface height observations. The same initial condition and the same forcing fields were used for these experiments. They differ only in the MDT used to compute the absolute dynamic topography assimilated into the system: MDT1 for EXPT1, MDT2 for EXPT2, and MDT3 for EXPT3

In a second stage, a fifth simulation, called EXPT4, is performed over the same period (October 1992-December 1993). In EXPT4, TS profiles are assimilated in addition to the surface data and MDT2 is used. The methodology is described in the section on the assimilation of TS profiles.

In this study, we present different diagnostics of these simulations. Focusing on the North Atlantic region, these diagnostics are all calculated from the model forecasts, before statistical correction, and over the year 1993 (from January to December).

\section{Sensitivity Tests: Results}

The system response is analyzed for the first set of simulations. The ability of the model, $\mathbf{3 3 0}$ with assimilation, to reproduce the essential elements of the North Atlantic circulation is discussed. The sensitivity of the solution to the different MDTs is analyzed.

For this study, we assume that the assimilation results have already been validated. The diagnostics presented here are (1) the surface currents which are directly related to the changes in MDT through geostrophy and are crucial for climate studies and many $\mathbf{3 3 5}$ operational applications; and (2) the mean barotropic streamfunction as an expression of the vertically integrated circulation pattern. A temperature section along $55^{\circ} \mathrm{W}$ is also examined to consider the sensitivity of the solution in terms of thermohaline characteristics.

\section{Surface Currents}

Figure 5 shows the difference between the simulations in terms of the mean currents for $\mathbf{3 4 0}$ 1993 at $50 \mathrm{~m}$ depths. The classical surface currents of the North Atlantic are clearly visible in all solutions but, as expected, there are also important regional differences.

The mean flow of the Florida Current is particularly strong in the control run and in EXPT3, where it exceeds $90 \mathrm{~cm} / \mathrm{s}$, while it is about $55 \mathrm{~cm} / \mathrm{s}$ in EXPT1 and $65 \mathrm{~cm} / \mathrm{s}$ in EXTP2. This result is coherent with the local gradients of the different MDTs, which are $\mathbf{3 4 5}$ more realistic in EXPT0 and EXPT3 (Fratantoni 2001). Although the corresponding current velocities are greater in EXPT3, the GS extension and the NAC pathway are fairly similar in all assimilation solutions. The NAC turns north around $45^{\circ} \mathrm{W}$, and then northeast around $40^{\circ} \mathrm{W}$. While it is around $30 \mathrm{~cm} / \mathrm{s}$ in EXPT1 and exceeds $40 \mathrm{~cm} / \mathrm{s}$ in EXPT3 and the control run, it is significantly weaker in EXPT2, with a mean speed of around $20 \mathrm{~cm} / \mathrm{s}$. The latter $\mathbf{3 5 0}$ value is too low (Frantatoni 2001). In all assimilation experiments, the Azores Current is shifted to the south and its flow slightly increased. From less than $10 \mathrm{~cm} / \mathrm{s}$ in the control run, its speed reaches around $12 \mathrm{~cm} / \mathrm{s}$, with a maximum of $15 \mathrm{~cm} / \mathrm{s}$, in EXPT1, EXPT2, and EXPT3 near $25^{\circ} \mathrm{W}$. 
a)

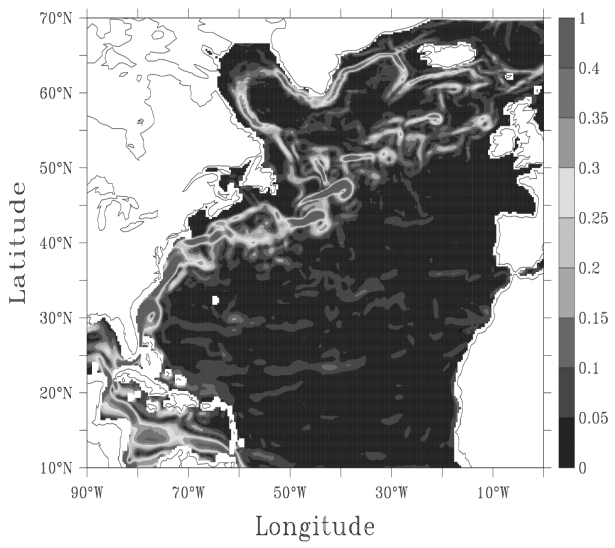

c)

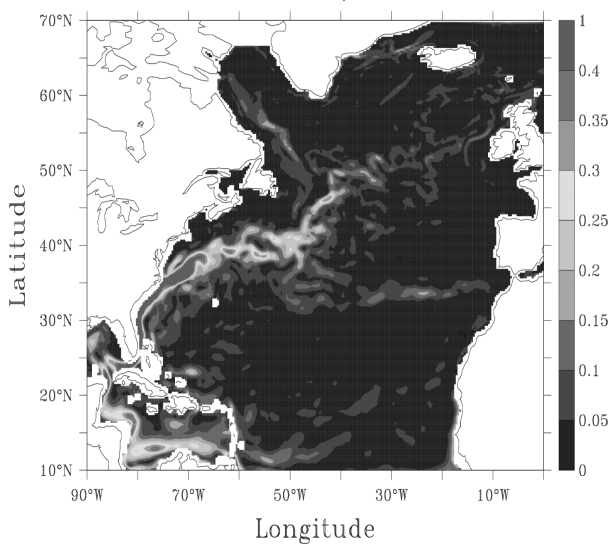

b)

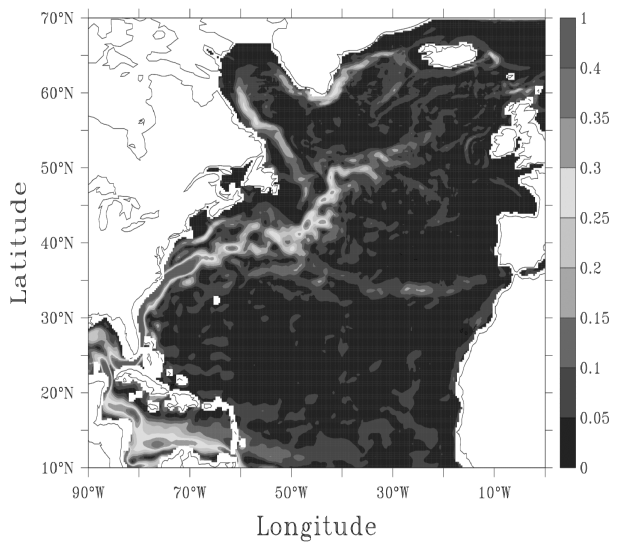

d)

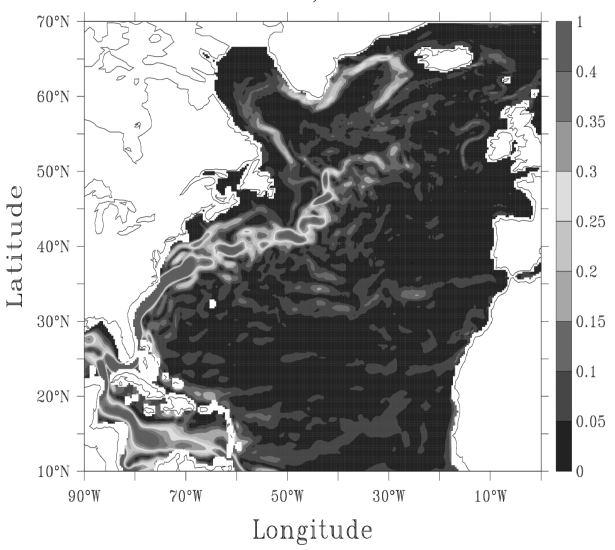

FIGURE 5 Mean surface current velocity for (a) control run EXPT0, (b) EXPT1, (c) EXPT2, and (d) EXPT3 assimilation experiment.

North of $50^{\circ} \mathrm{N}$, the representation of the main surface current system is more variable from one experiment to another. In both the control run and EXPT3, west of $30^{\circ} \mathrm{W}$, one branch of the NAC turns northward to join the Irminger basin, before crossing the MidAtlantic Ridge. This branch is much weaker in EXPT1 and EXPT2. The North Atlantic Drift Current is particularly strong in the control run, with the mean surface current exceeding 20 $\mathrm{cm} / \mathrm{s}$ in some areas, which appears unrealistic. Observations highlight various branches of weak currents flowing to the northeast, rather than an intense and continuous flow (Reverdin et al. 2003). By contrast, in EXPT2, the surface currents are weak in the whole northeast region.

The East-West Greenland/Labrador Current system appears fairly different from one 365 solution to another. The corresponding mean currents are reduced in all assimilation experiments, and particularly in EXPT2. With a mean velocity of about $35 \mathrm{~cm} / \mathrm{s}$ in the control run, the Labrador current reaches $25 \mathrm{~cm} / \mathrm{s}$ in EXPT1 and around $15 \mathrm{~cm} / \mathrm{s}$ in EXPT2 and EXPT3. By comparison to Reynaud et al. (1995), the latter value is too weak With a mean speed of about $35 \mathrm{~cm} / \mathrm{s}$ in the control run, the West Greenland Current flows at around

$3705 \mathrm{~cm} / \mathrm{s}$ in EXPT2, around $15 \mathrm{~cm} / \mathrm{s}$ in EXPT1, and $20 \mathrm{~cm} / \mathrm{s}$ in EXPT3. In EXPT2, all the West Greenland Current turns west near $61^{\circ} \mathrm{N}$ whereas it turns west near $63^{\circ} \mathrm{N}$ in the control 
run; in EXPT1, and EXPT3, different branches exist between $60^{\circ} \mathrm{N}$ and $64^{\circ} \mathrm{N}$, which is in better agreement with observations (Cuny et al. 2002).

For each of the experiments, the regional differences in the simulated surface currents can be largely attributed to differences in the MDTs, moderated by the effect of the as- 375 similation. In EXPT2, the currents are generally weaker. In contrast, EXPT3 exhibits the highest current values. This can be related to the MDT resolution; whereas, MDT2 is the smoothest MDT solution and MDT3, which was deduced from a $1 / 12^{\circ}$ free-run simulation, has the highest resolution.

\section{Barotropic Streamfunction}

Figure 6 shows the 1993 mean barotropic streamfunction for the four simulations. Note first that changes introduced by assimilation are significant. Barotropic transport is increased by assimilation, and the increase is much larger in EXPT1 and EXPT3 than in EXPT2. At the global scale, all simulations show well-developed gyres of similar structure, though they all differ in amplitude. At the regional scale, however, differences in structure may also be observed.

The Northwestern subtropical gyre limit has drifted southward with the assimilation, thus correcting the GS pathway. Both the transport associated with the Florida Current/Gulf

a)

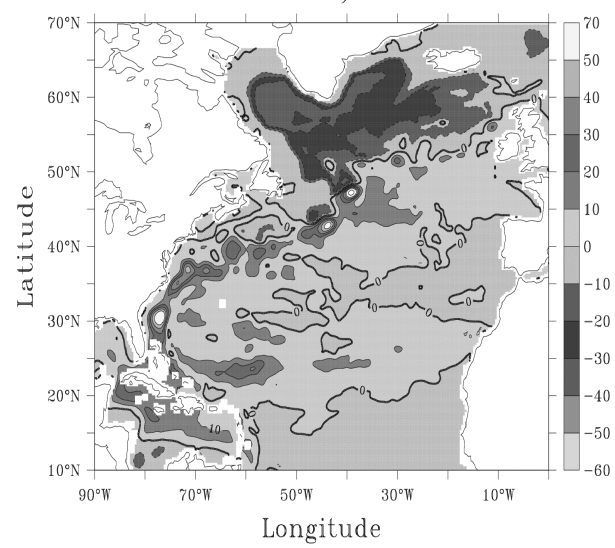

c)

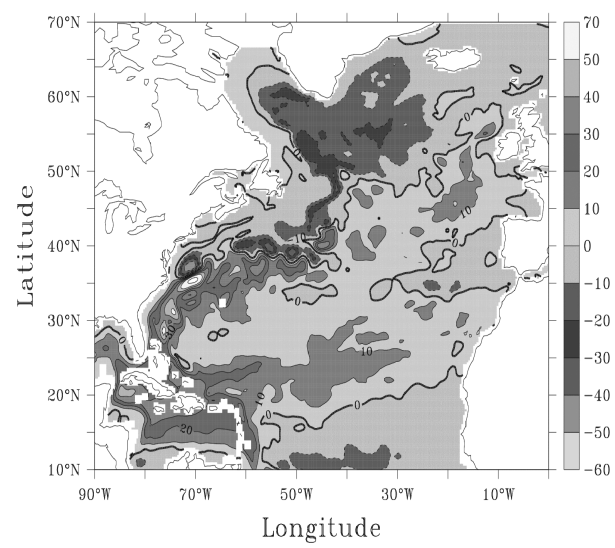

b)

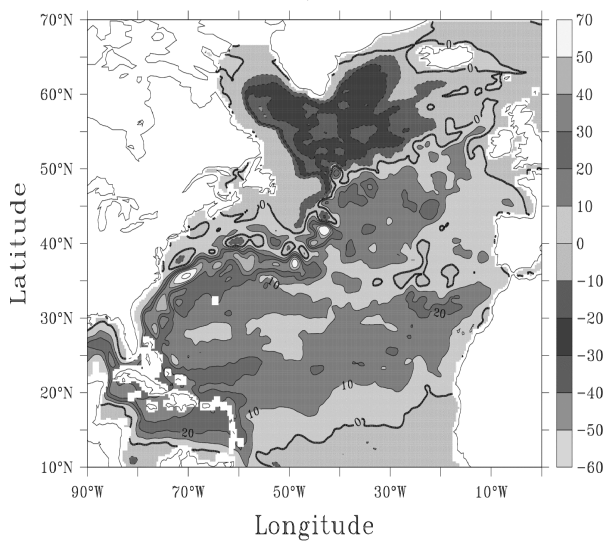

d)

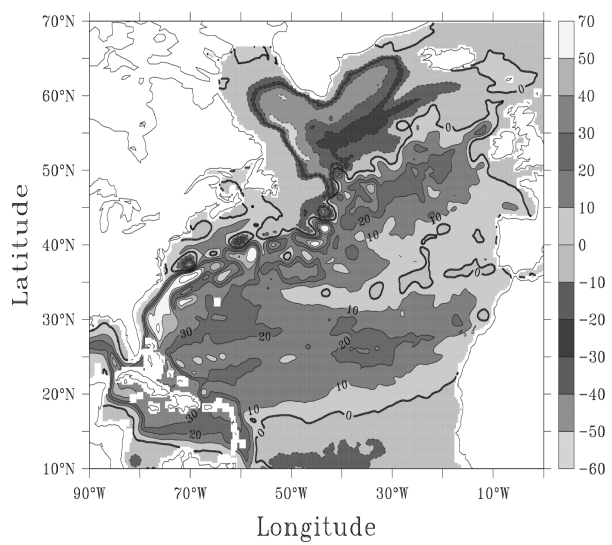

FIGURE 6 Mean barotropic streamfunction for (a) control run EXPT0, (b) EXPT1, (c) EXPT2, and (d) EXPT3 assimilation experiment. 
Stream system and the associated recirculation are more pronounced in EXPT1 and EXPT3

390 than in the other solution. Numerous small cells are found along the GS and NAC paths, which have been shifted by the assimilation along the line of maximum gradient of mean dynamic topography. These small-scale structures are very different from one solution to the next but are much larger and stronger in EXPT1 and EXPT3. This feature can be related to the presence of small-scale structures along the subtropical front in MDT1 and MDT3 that are almost absent in MDT2.

The amplitude of the subpolar gyre also differs significantly. With a magnitude of approximately $30 \mathrm{~Sv}$ in the control run, it maintains approximately the same magnitude in EXPT1, increases to $50 \mathrm{~Sv}$ in EXPT3, and decreases to a value of $20 \mathrm{~Sv}$ in EXPT2. Significant differences are also observed in its structure. The location of maximum transport varies.

400 Both subpolar gyre structure and maximum transport location observed in the solution are clearly correlated with the subpolar gyre structure and minimum mean sea level location of the different MDTs.

\section{Vertical Temperature Section at $55^{\circ} \mathrm{W}$}

As already observed in the previous section, the assimilation of surface data modifies the representation of not only the sea surface fields, but also the entire ocean state, through a vertical extrapolation of sea surface information. In this section, we analyze the sensitivity of the interior thermohaline properties to the use of different MDTs in the assimilation system.

Figure 7a represents the thermal structure along the $55^{\circ} \mathrm{W}$ section from Levitus 98 cli-

410 matology, while Figures 7b, 7c, 7d, and 7e show the differences along this section between the mean thermal structure of, respectively, the control run, EXPT1, EXPT2, EXPT3, and the climatological thermal structure of Figure 7a. Assimilation strongly modifies the subsurface temperature structure and significant differences are observed from one experiment to another.

415 In the Labrador Sea, temperatures in the control run are more than $2^{\circ} \mathrm{C}$ too warm over the Northern and Southern limits of the Labrador Sea, where the West Greenland/Labrador Current system flows. In the assimilation runs, these anomalies have been reduced and even replaced by a cold anomaly in the Northern part of around $0.5^{\circ} \mathrm{C}$ in EXPT2. In the interior basin, the temperature is colder from the surface to the bottom in all assimilation runs, but

420 the amplitude of cooling varies from one experiment to another.

The most marked anomaly with respect to the climatology is observed in the control experiment north of $40^{\circ} \mathrm{N}$, just south of Newfoundland. Subsurface temperatures are as much as $5^{\circ} \mathrm{C}$ too warm in the upper 500 meters, associated with the large-scale "misplacement" of warm water from the Gulf Stream extension (located around $41^{\circ} \mathrm{N}$ ) and the associated absence of colder Labrador Current water near the continental shelf. This anomaly has been considerably reduced in all assimilation experiments, especially in EXPT2 and EXPT3. The differences observed in the amplitude of this anomaly reduction are due to the presence of a small northern branch of the GS present near $45^{\circ} \mathrm{N}$ (its signature is also observed on Figure 5), preventing colder water from the Labrador Sea turning southwest around Newfoundland. This current becomes weaker in EXPT2 than in EXPT1 and EXPT3, which explains the differences in the thermal structure observed in this area in the different assimilation simulations. Parallel to the observed decrease in the warm anomaly, a negative feature of $2^{\circ} \mathrm{C}$ amplitude appears north of $40^{\circ} \mathrm{N}$, between depths of $500 \mathrm{~m}$ and $1000 \mathrm{~m}$ in EXPT2. This negative feature can be associated with the change in Labrador Sea water mass characteristics noted in the previous paragraph.

In the midlatitudes, between $20^{\circ} \mathrm{N}$ and $40^{\circ} \mathrm{N}$, the control run is too warm between approximately $100 \mathrm{~m}$ and $600 \mathrm{~m}$ compared with the climatology. This feature is significantly 
amplified in both location and amplitude by the assimilation in EXPT3, an anomaly that corresponds to the presence of $18^{\circ} \mathrm{C}$ Mode Water formed in the Sargasso Sea. In the climatology, this water mass has a temperature of $17^{\circ} \mathrm{C}-18^{\circ} \mathrm{C}$ (Figure $7 \mathrm{a}$ ) and extends between depths of $200 \mathrm{~m}$ and $450 \mathrm{~m}$. In all model runs, the water mass is too warm with a temperature of around $19^{\circ} \mathrm{C}$. The misrepresentation of water mass structure results in a stronger positive anomaly in EXPT3, where it is too deep.

LONGTUOE : $55 \mathrm{~N}$

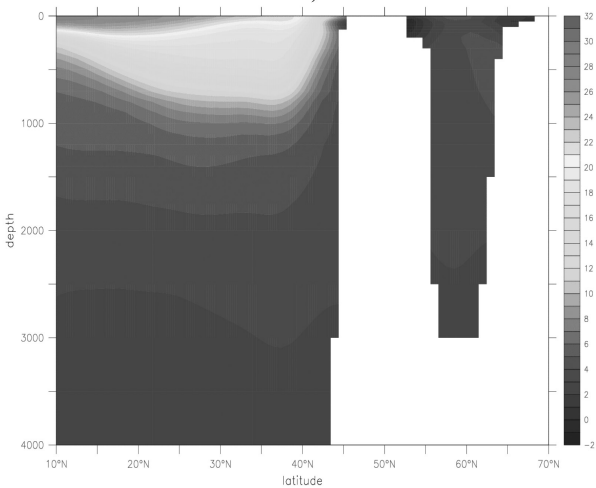

c)

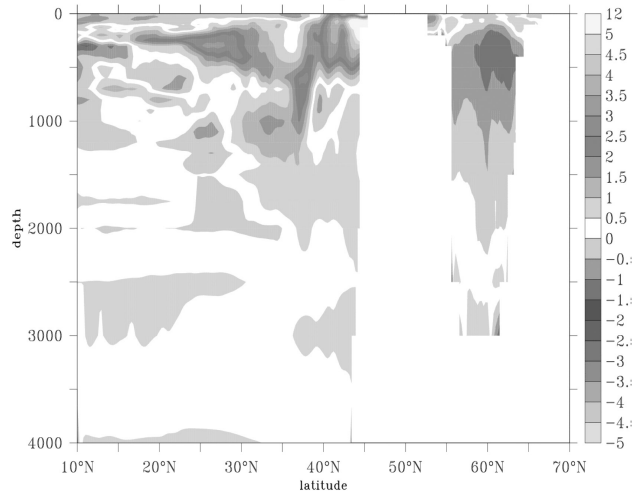

e)

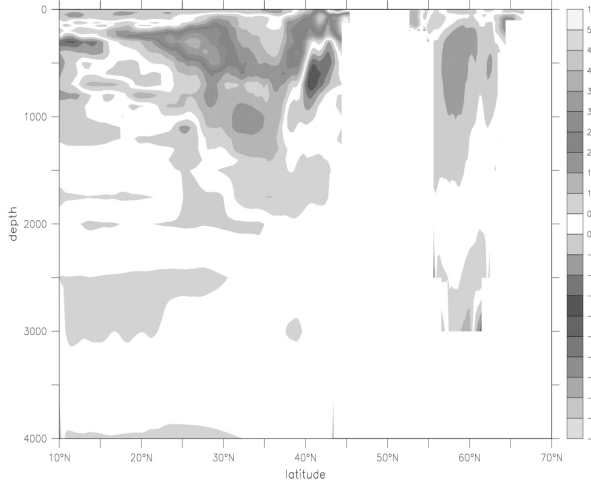

LONGIUDE : 55W

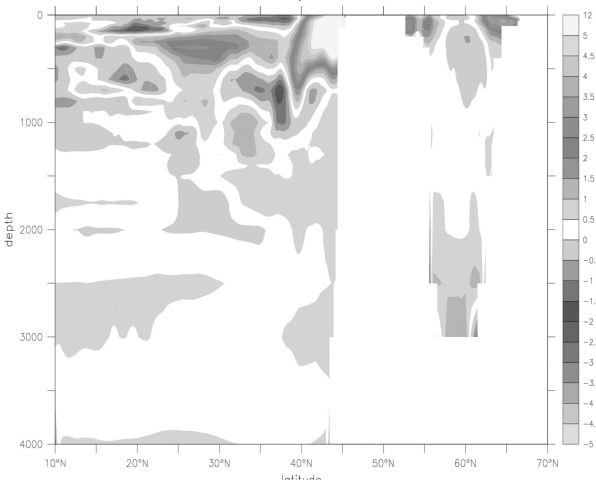

d)

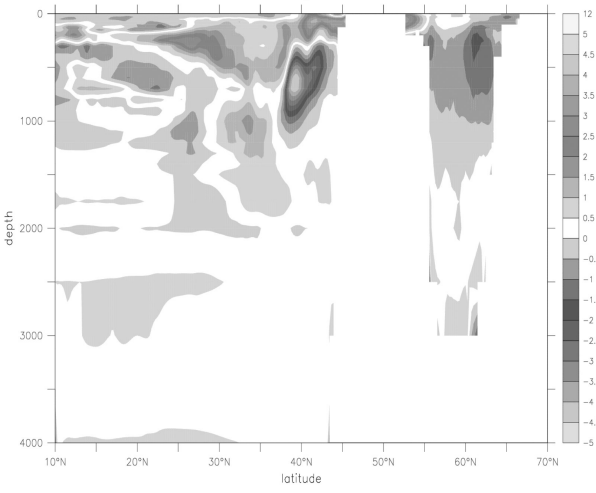

f)

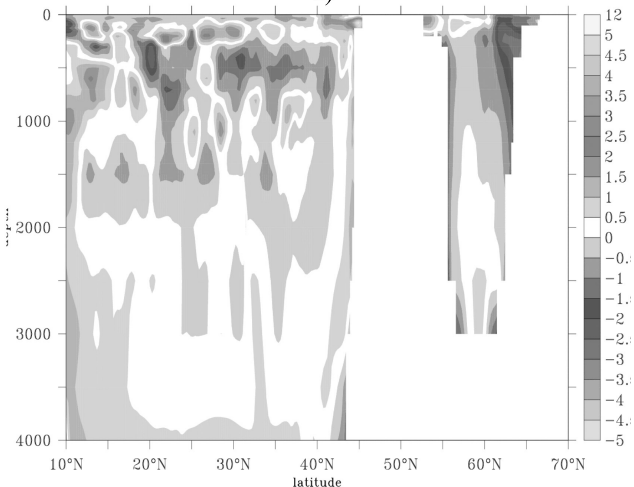

FIGURE 7 (a) Temperature section along $55^{\circ} \mathrm{W}$ from Levitus climatology. Anomaly between the mean temperature from (b) control run, (c) EXPT1, (d) EXPT2, (e) EXPT3, (f) EXPT4, and the climatological temperature field along $55^{\circ} \mathrm{W}$. 
The results of this section illustrate the impact of the choice of the MDT product on different ocean estimates. Although the impact of assimilation is generally positive, the different experiments do not perform equally well everywhere. The surface currents and the deep properties are very sensitive to the change in mean dynamic topography, in particular where gradient differences are observed. In addition, the MDT, through different mechanisms, also has an impact on a wide range of model oceanic processes, such as volume transport and thermohaline circulation which are shown to be very sensitive quantities.

\section{Comparison with Independent TS Profiles}

Another way to compare results is to validate each experiment using in situ data. For this purpose, the model thermal and salinity fields were compared to (a) the climatology and (b) an ensemble of XBT profiles collected in the North Atlantic. Figure 8 shows the distribution of available XBT in 1993.

RMS misfits between the XBTs or climatology and the equivalent model state were computed for both the Gulf Stream region and the Labrador basin and are shown in Figure 9. For each assimilation experiment, the continuous-line curve represents the forecast and the dashed-line curve the analyses (after dynamical adjustment). There is little difference between analyses and forecasts, indicating a stable assimilation system. Here, the discussion is limited to the results of the experiments where no TS profiles are assimilated.

In the Gulf Stream region, where the results are particularly sensitive, EXPT1 and EXPT3 are closer than the free run to both climatology and XBTs down to a depth of at least $400 \mathrm{~m}$. However, EXPT2 shows better results than EXPT1 and EXPT3 down to a depth of $700 \mathrm{~m}$, with misfits remaining better than the free run. Note that the vertical structure of the temperature misfits exhibits a local maximum around $100 \mathrm{~m}$ depth, which is related to the difficulty in correctly simulating the mixed layer depth. This maximum is greatly reduced by the assimilation, particularly in EXPT2. Note also that the error in salinity is also reduced, due to the assimilation of surface salinity observations.

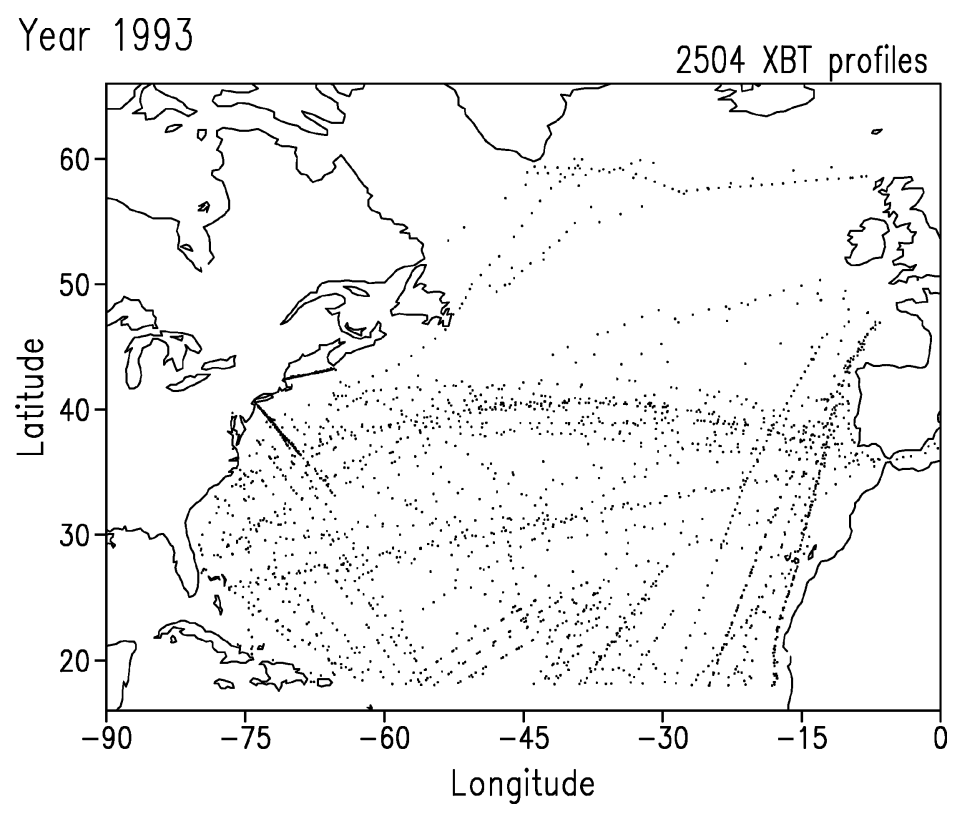

FIGURE 8 Horizontal distributions of XBT profiles available during 1993 (SISMER). 
a)
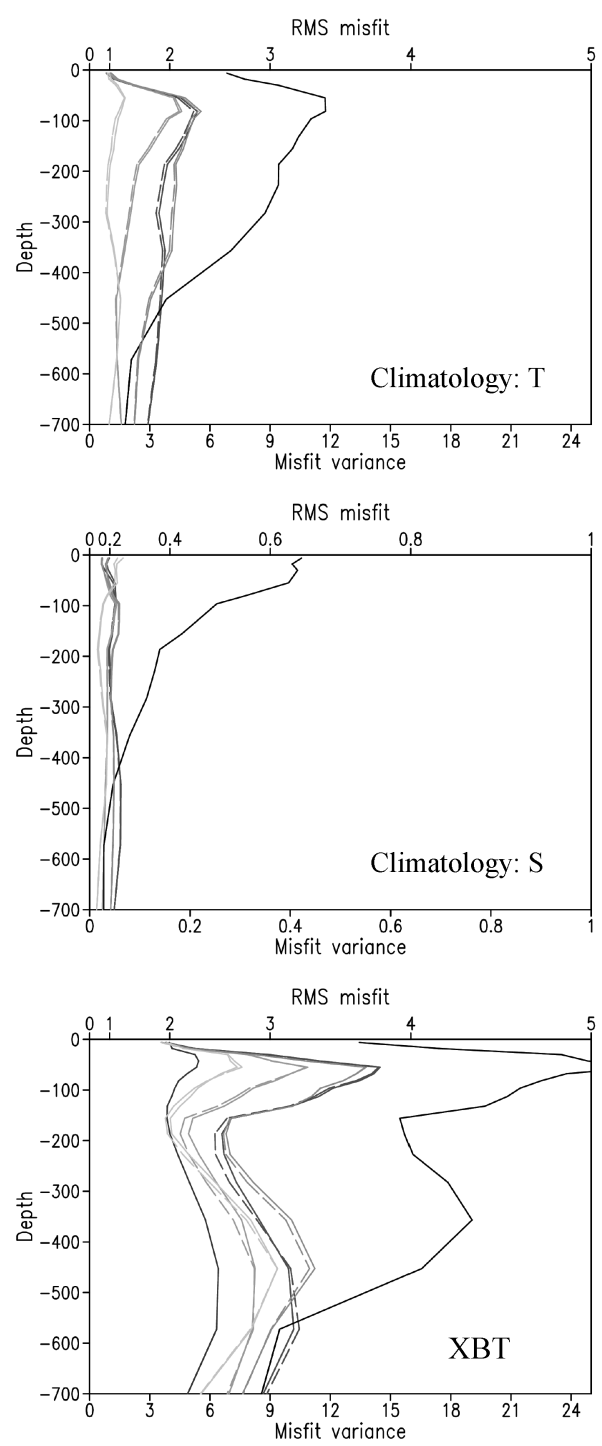

b)
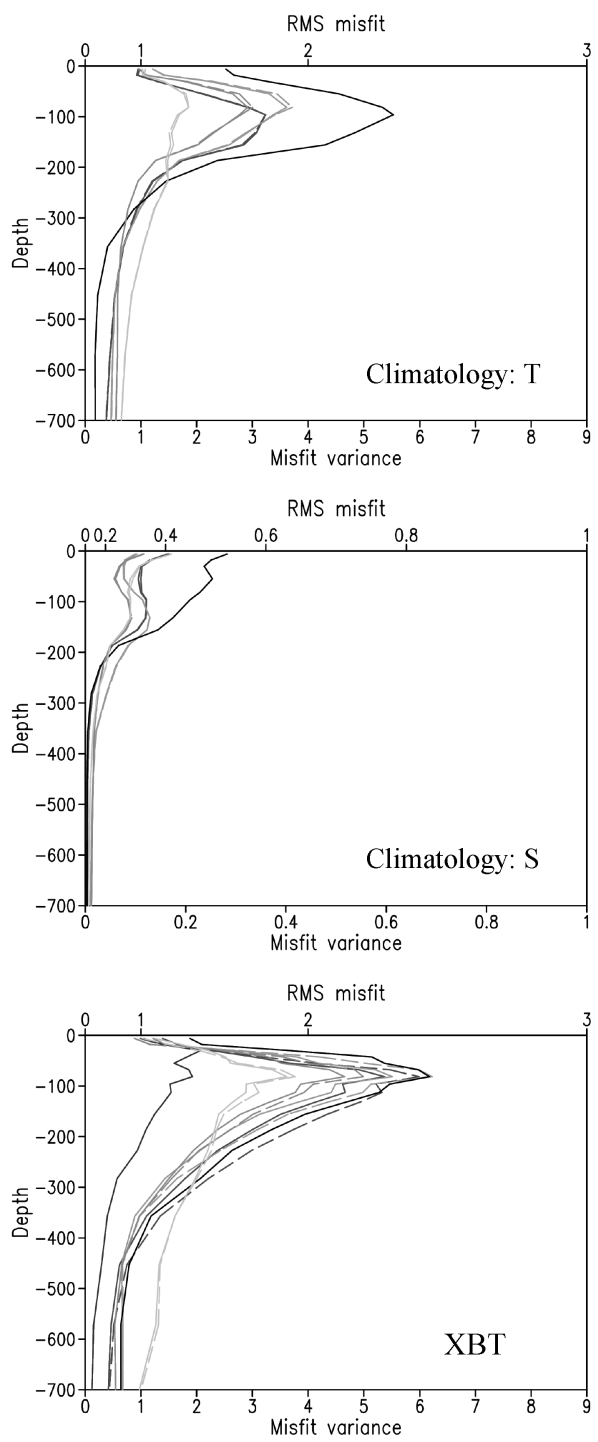

FIGURE 9 Temperature $\left({ }^{\circ} \mathrm{C}\right.$ ) and salinity (PSU) RMS misfit with respect to TS climatology and to XBT profiles in (a) the Gulf Stream region and (b) the Northeast region, down to $700 \mathrm{~m}$ and averaged for 1993. The figure shows plots of the free run (black curve), the EXPT1 (turquoise), EXPT2 (green), EXPT3 (red), and EXPT4 (yellow) solutions. For each assimilation experiment, the 3-day forecast is shown by the continuous-line curve and the analyses by the dashed-line curves.

In the Labrador region, the results are different. Here again, the impact of assimilation is positive, but the differences between the temperature misfits of EXPT1, EXPT2, and EXPT3 are less marked, due to a much weaker vertical temperature gradient. In this region, EXPT1 shows slightly better results. 


\section{Specific Case of the Assimilation of TS Profiles}

475 In a multivariate case, the Kalman gain generates corrections based on specified cross-field error covariances. Errors in surface fields are related to errors in subsurface. Consequently, when the system is constrained only by surface observations, inaccuracy in cross-field covariances will lead to inaccurate corrections in water mass properties at depth. Given our limited knowledge of model errors and the associated correlations, this is a significant

480 limitation on the quality of ocean predictions. The assimilation of new observations, such as TS fields, should moderate this problem.

However, this also means the introduction of new information types in the system, that is, of heterogeneous variables. The question we wish to address here is the problem of consistency between the sea level elevation corrections provided, on one hand, by the

485 MDT information and, on the other, by the TS profiles. Indeed, there is no reason why these different data sources should contain exactly the same information about the $S 0$ and $S 1$ components defined previously in the section on problem definition. Note that this difficulty would not arise (1) if the model had not drifted from its initial climatological state, (2) if both fields were not associated with large errors, and (3) if the conventional sea

490 level reference was the same for the model and the data.

In order to overcome potential difficulties, we adopted the following strategy. Based on the definition in the problem definition section, a new $S 0$ horizontal mean level was determined using in situ profile information, whereas the $S 1$ component was prescribed using the MDT. This approach amounts to an estimation of the sea level topography in two steps. First, we assume no possible connection between errors in sea level elevation and errors in the subsurface fields. In practice, it means that we have dropped the cross-field correlation to zero in the forecast error covariance. Thus, the sea level elevation correction will be constrained only by sea surface observations. Second, modifications are introduced into the adjustment operator in order to take advantage of the TS data content for the estimate

500 of corrected sea level elevation. The density field is deduced from the analyzed vertical fields (after restoration of the hydrostatic assumption). The corresponding sea surface topography is calculated and compared to the analyzed sea surface topography prescribed by the filter. The horizontal mean difference between these two fields is then computed and added to the analyzed sea surface topography. In this way, we also expect to correct progressively

505 the bias introduced in the initial state by model drift. This approach was used to perform EXPT4.

In order to test this method, we show in Figure 10 the temporal evolution of mean sea surface heights averaged over the whole model domain corresponding to EXPT0, EXPT2, and EXPT4. The free run simulation drifts slowly away from its initial state with time

510 because the model thermal content is increasing during the numerical experiment Using surface observations only, the SEEK filter eliminates this model drift by controlling the mean sea level trajectory from the initial assimilation date (EXPT2 curve). The behavior of the EXPT4 curve is different. After a first stage in which mean sea surface height decreases, it stabilizes and starts reproducing the same seasonal variability as the EXPT2 curve: a new

515 S0 value based on the TS information has been determined. It means that, with the proposed method, we are able to use climatological subsurface observations correctly to reduce the error in the initial mean state and then to improve significantly the model trajectory.

An analysis is also conducted on the representation of water mass properties in EXPT4. A comparison of Figure $7 \mathrm{f}$ with the other figures (particularly Figure $7 \mathrm{~d}$, where the same

520 MDT was used) shows that in EXPT4 temperature has generally been brought into better agreement with the climatology in the ocean interior. In particular, the $18^{\circ} \mathrm{C}$ mode water properties have been successfully modified. In mid-latitudes, the estimated temperature 


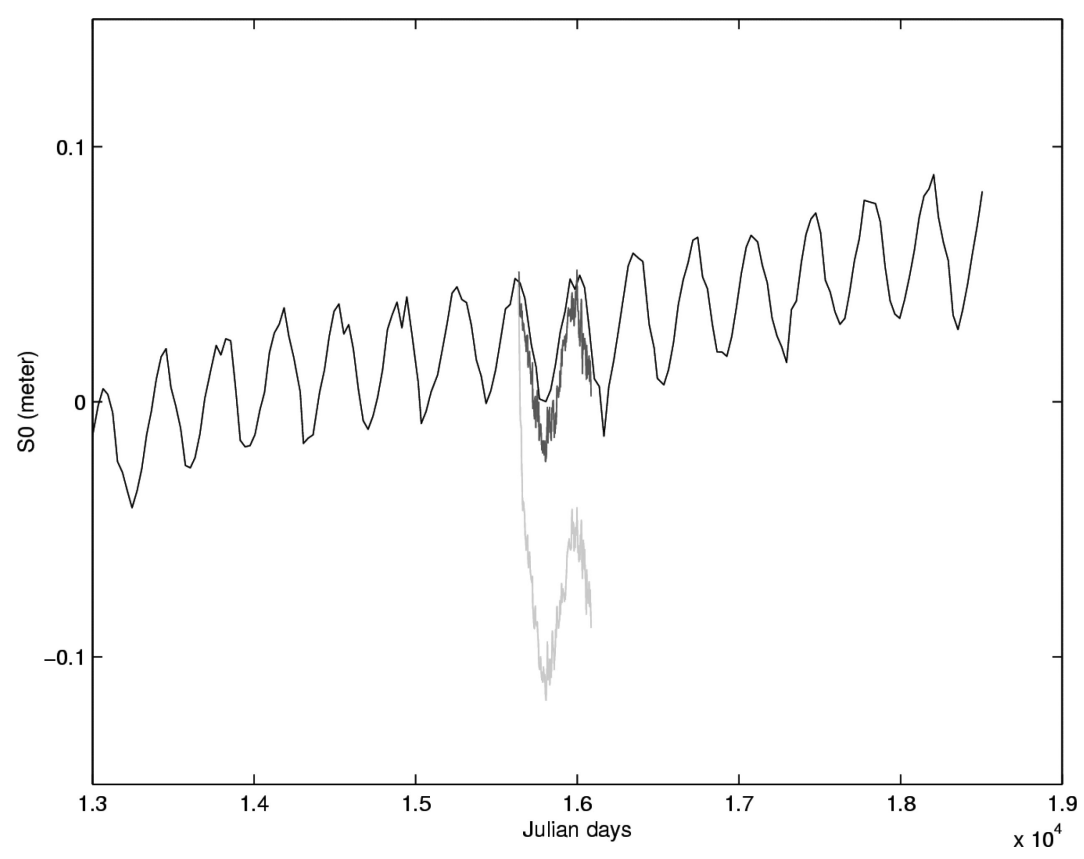

FIGURE 10 Time evolution of the sea surface elevation averaged over the model domain for EXPT0 (black), EXPT2 (red), and EXPT4 (green).

exhibits some small-scale colder features of less than $1{ }^{\circ} \mathrm{C}$ around $500 \mathrm{~m}$ depth. This might be due to a limitation of the system in producing accurate water mass property corrections using a limited number of error modes (10), when the number of degrees of freedom for $\mathbf{5 2 5}$ the problem is much greater. Finally, Figure 9 shows the resulting RMS misfit between the XBTs or climatology and the equivalent model state, also illustrating the positive impact of the assimilation of TS profiles.

These results illustrate that the corrections to the depth of the model isopycnic layers provided by the assimilation of TS profiles are accurately estimated. A specific TS profile assimilation experiment was performed without using this protocol (not shown), and the results suffered from significant errors in the estimation of depths for water mass correction.

\section{Summary and Conclusions}

The main objective of this work was to assess the sensitivity of simulated ocean state estimates to different MDT products in a multivariate assimilation context. Ongoing and $\mathbf{5 3 5}$ future satellite missions should provide accurate measurements of the gravity field over the ocean, but it will still take several years before precise estimates of the absolute dynamic topography are produced. In the near future, to compute this quantity we will still have to rely on estimates obtained using the different existing approaches.

In this study, we first presented three different experiments, assimilating SSH, SST, and $\mathbf{5 4 0}$ SSS observations into a hybrid vertical coordinate model of the North and Tropical Atlantic Ocean. In each experiment, a different MDT product was used to assimilate satellite sea level anomalies into the model. Important differences between the simulations were observed in terms of ocean circulation, transport, and thermohaline fields, which can be related to the differences between the three MDT estimates. The diagnostics demonstrate that the $\mathbf{5 4 5}$ assimilation system is sensitive to the choice of the MDT, not only in terms of surface 
currents, but also in terms of deep properties. It remains difficult to determine which MDT estimate is the most appropriate for assimilation. With regard to the different diagnostics presented, and particularly to the systematic comparison with in situ TS profiles, the results

550 vary from one oceanic region to another. In conclusion, errors in MDT estimates are shown to be among the most important factors affecting simulation quality.

An additional experiment was performed to evaluate the joint assimilation of dynamic topography and TS profiles. According to the protocol proposed, the MDT information was used to control the horizontal mean sea level pattern, while TS profiles were used to correct progressively the horizontal averaged sea level elevation. Assimilation of TS profiles proved efficient in correcting the significant error in the initial model state (largely due to model drift) and in making the vertical structure of the ocean more realistic. Finally, the study also underlines the necessity of ensuring consistency between MDT and in situ profiles.

\section{References}

560 Bleck, R., and D. Boudra. 1981. Initial testing of a numerical model framed in hybrid isopycnic/Cartesian model using a hybrid (quasi-isopycnic) vertical coordinate. J. Phys. Oceanogr. 11:755-770.

Brankart, J. M., C. E. Testut, P. Brasseur, and J. Verron. 2003. Implementation of a multivariate data assimilation scheme for isopycnic coordinate ocean models: Application to a 1993-96 hindcast of the North Atlantic Ocean circulation. J. Geophys. Res. 108(C3):3074; doi:10.1029/ 2001JC001198.

Brasseur, P., J. Ballabrera, and J. Verron. 1999. Assimilation of altimetric observations in a primitive equation model of the Gulf Stream using a Singular Extended Kalman filter. J. Mar. Syst. 22:269_ 294.

570 Chassignet, E. P., and Z. D. Garraffo. 2001. Viscosity parameterization and the Gulf Stream separation. pp. 37-41 in From Stirring to Mixing in a Stratified Ocean, Proceedings 'Aha Huliko'a Hawaiian Winter Workshop, U. of Hawaii, January 15-19, 2001, P. Muller and D. Henderson, Eds.

Chassignet, E. P., L. T. Smith, G. R. Halliwell, and R. Bleck. 2003. North Atlantic simulation with the HYbrid Coordinate Ocean Model (HYCOM): Impact of the vertical coordinate choice, reference

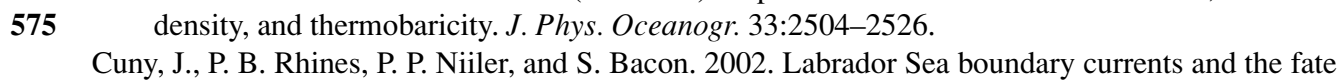
of the Irminger Sea Water. J. Phys. Oceanogr. 32:627-647.

Ducet N., P. Y. Le Traon, and G. Reverdin. 1999. How accurately can we map the mesoscale ocean surface variability from the combination of T/P and ERS-1/2 altimetric data? Int. WOCE Newsletter 37:40-43.

Durand, F., L. Gourdeau, T. Delcroix, and J. Verron. 2003. Can we improve the representation of modeled ocean mixed layer by assimilating surface-only satellite-derived data? A case study for the Tropical Pacific during the 1997-1998 El Niño. J. Geophys. Res. 108(C6):3200; doi:10,1029/ 2002JC0011603.

585 Frantatoni, D. M. 2001. North Atlantic surface circulation during the 1990's observed with satellitetracked drifters. J. Geophys. Res. 106:22067-22093.

Halliwell, G. R. Evaluation of vertical coordinate and vertical mixing algorithms in the HYbrid Coordinate Ocean Model (HYCOM). Ocean Modelling. In press.

Hernandez, F., P. Schaeffer, M. H. Calvez, J. Dorandeu, Y. Faugre, and F. Mertz. 2001. Surface moyenne océanique: Support scientifique à la mission altimétrique JASON-1, et à une mission micro-satellite altimétrique. Contrat SSALTO 2945 -Lot 2- A.1, Rapport n CLS/DOS/NT/ 00.341 .

Killworth, P. D., C. Dieterich, C. Le Provost, A. Oschlies, and J. Willebrand. 2001. Assimilation of altimetric data and mean sea surface height into an eddy-permitting model of the North Atlantic. Progr. In Oceanogr. 48:313-335.

Li, J. G., P. D. Killworth, and D. A. Smeed. 2003. Response of an eddy-permitting ocean model to the assimilation of sparse in-situ data. J. Geophys. Res. 108(C4):3111; doi:10.1029/2001JC001033. 
Mercier, H. 1986. Determining the general circulation of the ocean: A non-linear inverse problem. J. Geophys. Res. 91:5103-5109.

Mitchell, J. L., J. M. Dastugue, W. J. Teague, and Z. R. Hallock. 1990. The estimation of geoid 600 profiles in the Northwest Atlantic from simultaneous satellite altimetry and airborne expendable bathythermograph sections. J. Geophys. Res. 95:17965-17977.

Penduff T., P. Brasseur, C. E. Testut, B. Barnier, and J. Verron. 2002. A four-year eddy-permitting assimilation of sea-surface temperature and altimetric data in the South Atlantic Ocean, J. of Marine Res. 60:805-833.

Pham D. T., J. Verron, and M. C. Roubaud. 1998. Singular evolutive extended Kalman filter with EOF initialization for data assimilation in oceanography. J. Mar. Syst. 16:323-340.

Reverdin, G., P. P. Niiler, and H. Valdimarsson. 2003. North Atlantic Ocean surface currents. J. Geophys. Res. 108: 